\title{
Optimum Feeder Routing and Distribution Substation Placement and Sizing using PSO and MST
}

\author{
Ihsan Jabbar Hasan, Chin Kim Gan*, Meysam Shamshiri, Mohd Ruddin \\ Ab Ghani and Rosli Bin Omar \\ Faculty of Electrical Engineering, Universiti Teknikal Malaysia Melaka (UTeM), Hang Tuah Jaya, 76100 \\ Durian Tunggal, Melaka, Malaysia; ckgan@utem.edu.my.
}

\begin{abstract}
A long term distribution network planning consists of several complexity aspects due to the multiple decision variables in objective functions. Optimum placement of distribution substations and determination of their sizing and feeder routing is one of major issues of distribution network planning. This paper proposes an algorithm to find the optimum distribution substation placement and sizing by utilizing the PSO algorithm and optimum feeder routing using modified MST. The proposed algorithm has been evaluated on the distribution network case with 500 consumers which are consisting of residential and commercial loads. The test network is generated by fractal based distribution network generation model software tool. The results indicate the proposed algorithm has been succeeded to find the reasonable placement and sizing of distributed generation with adequate feeder path.
\end{abstract}

Keywords: Distribution Substation Placement, MST, MV \& LV Feeder Routing, OpenDSS, PSO

\section{Introduction}

The distribution network is a vital part of the electric power system. Distribution planners are always encountered with several difficulties in designing due to the numbers of decision variables which are influenced to distribution networks. Feeder routing in LV network and MV/LV substation placement and sizing are always one of the important challenges in distribution network planner. Meanwhile, it is crucial to reconfigure the existing distribution network due to the high load density and incremental cost of power distribution equipment and significant power losses in LV network (which is $50 \%$ of the total losses of power system).

Many researchers discuss about the complexity and difficulty of distribution system planning. $\operatorname{In}^{1}$ the optimal feeder routing problem using the dynamic programming technique and Geographical Information Systems (GIS) facilities has been performed. The total cost of investment, line losses and reliability has been taken to the account with related constraints such voltage drop and thermal issues. $\mathrm{In}^{2} \mathrm{GA}$ has been used to solve the optimum planning of large distribution network based on loss characteristics matrix for optimum substation location and graph theory for feeder routing in real size of distribution network. $\operatorname{In}^{3}$ the optimal planning of radial distribution networks using simulated annealing techniques. The paper addressed the minimum capital cost by applying the steepest descent approach as initial solution and improved the obtained cost with simulated annealing method. There are several method for distribution network modeling and planning which reference ${ }^{4}$ has reviewed the some research work under normal condition and emergency planning and modeling. In reference ${ }^{5}$ an attempt to reduce the cost of feeders by selecting the optimal conductor type and size of feeders segment. The paper performed a new computer algorithm and heuristic optimization technique.

*Author for correspondence 
Power flow solution is one of the important sections of distribution network planning due to the vast of the network. Therefore, this paper has tried to use OpenDSS engine as power flow calculator in distribution network planning in order to extract the voltages and losses of the network during optimization procedures.

This paper performed the PSO algorithm to find the optimal placement of substation and MST algorithm for optimal feeder routing in LV and MV networks.

\subsection{Particle Swarm Optimization (PSO)}

The swarm intelligent algorithm is one of the evolutionary computation methods which has introduced to solve the optimization problems and since then, their ability to be used in optimization problems has been demonstrated ${ }^{6}$. In this method, the movement towards the optimal position is obtained from the best information of each particle which is included in the initial population (Best Personal Position) and the optimal position that is found by the neighbor's positions (Best Global Position).

Researcher applied PSO algorithm successfully in complex non-linear engineering problem, principally in planning of distribution system, control systems, multi-objective optimization problems with multiple constraints, shape optimization and etc $^{7}$. Since the capacitor installation in distribution system has the non-linear and discrete equation, therefore, this paper utilized PSO algorithm as one of the accurate methods to solve the substation placement and sizing problem. The procedures of this algorithm have been described in ${ }^{8,9}$. Figure 1 shows the particle movements bases on PSO algorithm.

\subsection{Minimum Spanning Tree (MST)}

This theory is assigned as one of the important part of mathematic sciences which has been introduced in 19s century. A graph is a collection of ordered pairs of branches and nodes that can be written as $G \equiv(V, E)$. Where, $\mathrm{V}$ is node and $\mathrm{E}$ is branch. In fact, a graph is a diagrammatic model of a system. In general, a graph represents a binary relation between their system components. A single graph can have many different spanning trees that each branch can assign by weight. MST is the graph with the minimum weight on branches. There are a lot of algorithm to solve the MST problems which are Kruskal's algorithm, Prim's algorithm Dijkstra's algorithm and etc. In $^{2}$ the MST algorithm has been implemented as feeder routing solution in distribution networks. This paper uses the prim's

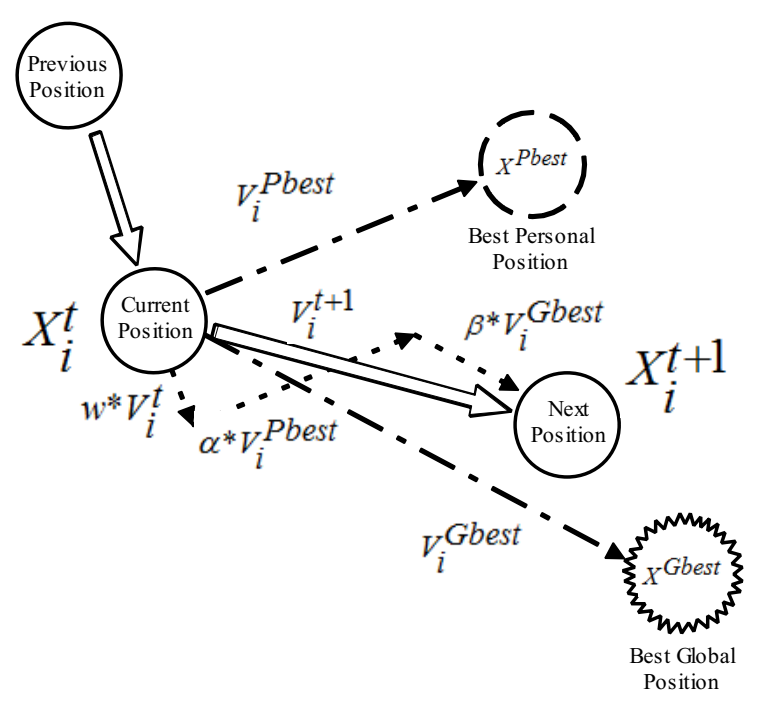

Figure 1. Principle of the PSO particle movement.

algorithm to solve the optimum feeder routing on LV and MV networks.

\subsection{OpenDSS}

The power flow calculation is required in planning of distribution network to evaluate the network. To obtain this reason, the Open Distribution System Simulator (OpenDSS) is a comprehensive electrical system simulation tool for electric utility distribution systems. The OpenDSS is an open source developed by the Electric Power Research Institute ${ }^{10}$. The OpenDSS engine includes the COM interface which can be used in other simulation programs such as MATLAB, VBA, C\# and etc. The OpenDSS engine can help the researchers to obtain the variety of significant information about the simulated power system. In this paper, OpenDSS engine is utilized as a power flow solution in order to find the power system parameters such voltage profile, power factor, real and reactive power flowing in each line, power losses and etc. which can be used in optimum substation placement and sizing problem in distribution networks.

\section{Methodology}

Based on the new prospect of distribution networks planning which is target to bring the small scale of substation beside the load centers in order to reduce the distribution network losses, this paper has tried to introduce the initial adjustments of the algorithm based on this 
purpose. Therefore, the minimum numbers of distribution substations are estimated based on the maximum branching rate and number of consumer (load centers) for each branch. In this paper, four branching rate for each substation and maximum 15 consumers have been selected for each branch. Which means; minimum $S_{n}$ substations are need for a network with $n$ branches and $m$ numbers of consumers for each branch, which $S_{n}$ can be written as follows:

$$
S_{n}=\frac{\mathrm{N}}{\mathrm{m} \times \mathrm{n}}
$$

where, $\mathrm{N}$ is the numbers of the consumers. Therefore, the estimation of minimum required substation can be consider as a first step of optimization algorithm that shown in Figure 2.

The optimum substation placement will perform after estimating the number of minimum required substations. For this purpose, the PSO algorithm has been utilized which it will be explained in following sub-section in

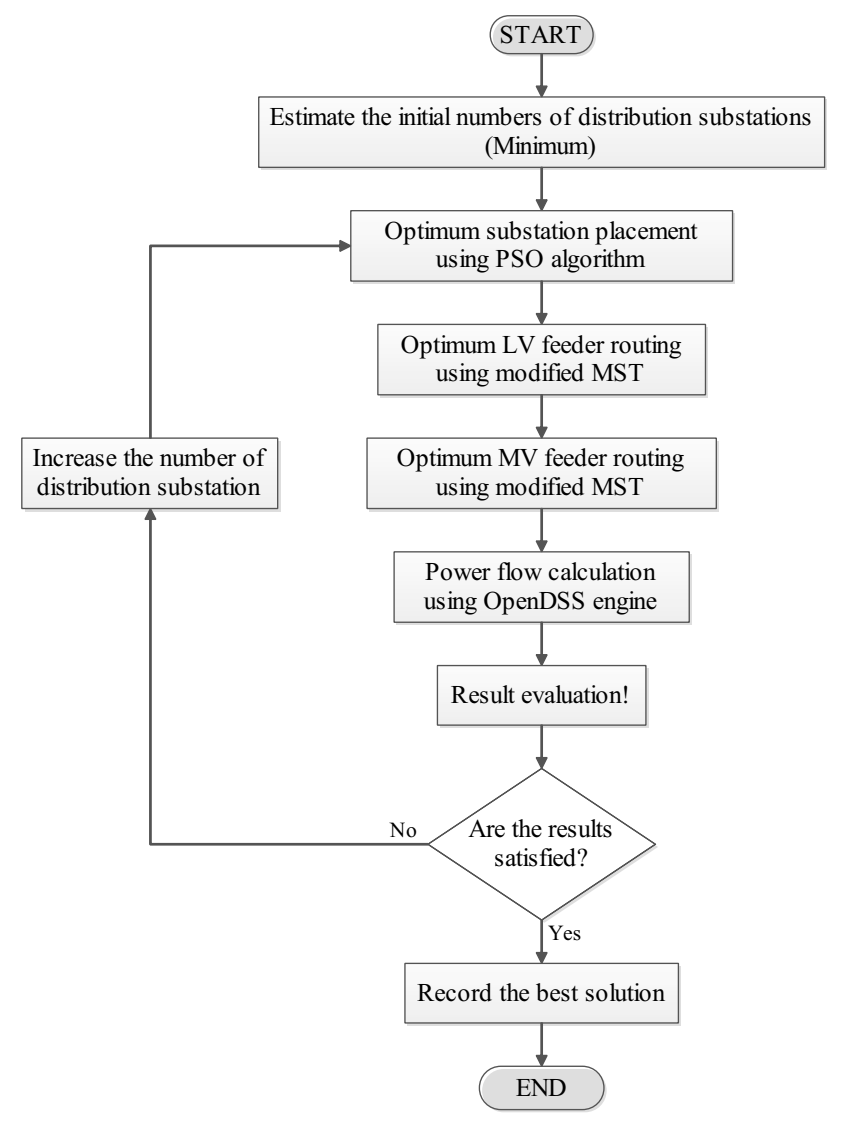

Figure 2. The proposed flowchart of optimum substation placement and sizing and feeder routing for distribution networks. details. The optimum substation placement and sizing algorithm will generate the coordinates of each substation which has been connected to the particular consumers with adequate substation require sizing based on the number of supplied consumers as shown in Figure 5. The next optimization step will be the optimum LV and MV feeder routing using modified MST algorithm. There are a few constraints and details that will be described in following related section. After indicates the paths of feeders the next algorithm step is power flow calculation using OpenDSS engine. Therefore, the algorithm is generated OpenDSS codes for designing the network to run the power flow and capturing required information for network assessment. The obtained results will be evaluated in the next step. The algorithm will record the captured solution, if the results have satisfied in terms of substation placement standards, desire losses and in range voltage profile. If not, the algorithm will repeat once more time by increasing the number of distribution substation. This loop will continues to find the best possible solution of the substation placement, routing and sizing whenever find the optimum network designing.

\subsection{Optimum Substation Placement Using PSO}

An adequate placement of distribution substation (MV/ LV) can be affected the other parts of distribution planning such as primary/secondary substations and feeders routing in network planning. In other word, if the placement of substation is not done with adequate precision, the technical and economic difficulties will be encountered to MV feeders and other parts of the distribution networks. Therefore, determining the proper placement of distribution substations is crucial. In this paper a comprehensive algorithm for substation placement and determining the number of substation has been utilized. The Particle Swarm Optimization (PSO) method is performed to optimize the best possible placement of distribution substations. The only substation placement problem has considered in this section. Figure 3 illustrates the PSO algorithm flowchart in terms of optimum distribution substation placement in LV network.

Figure 4 shows the consumers and candidate distribution substations with obtained from the fractal based distribution networks generation model tool ${ }^{11}$. Figure 5 shows the numbers of selected substations after optimization, which 16 numbers of distribution 


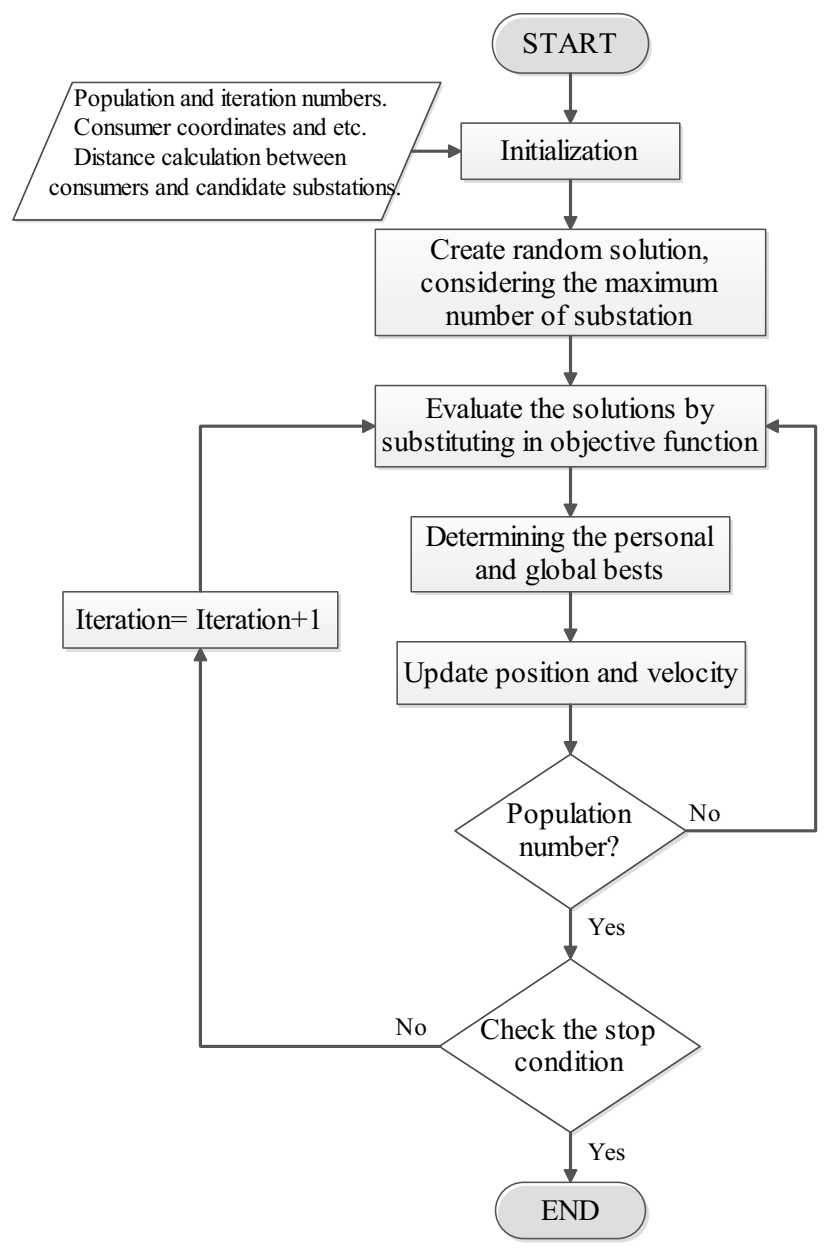

Figure 3. The optimum substation placement flowchart using PSO.

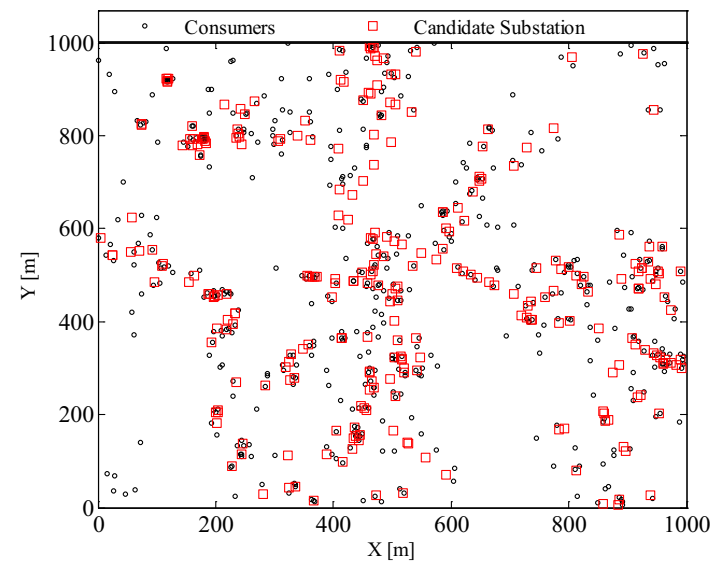

Figure 4. Consumers and candidate substation.

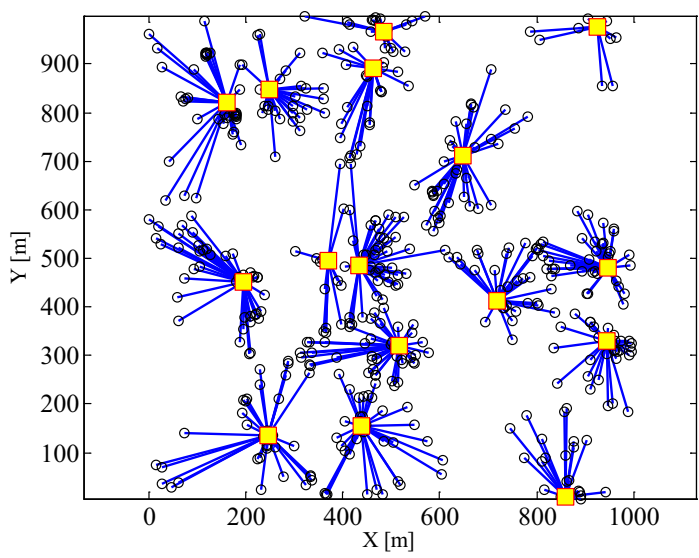

Figure 5. Selected MV/LV substations after optimization.

substations has been selected among the 275 candidate substations. Meanwhile, this figure indicates the numbers of consumers which assigned to their particular substation.

\subsection{Optimum Feeder Routing using MST}

As explained in introduction the prim's algorithm has been utilizes in this paper to find the optimum feeder routing of LV and MV networks. But the only prim's algorithm cannot carry out our desire optimal routing. The modified prim algorithm needs to be performed because of some technical requirement such as, open loop feeders and not allowed branches pass through each other. Figure 6 shows the proposed modification algorithm using prim's algorithm in MST in order to find the optimum feeder routing in distribution network.

Figure 7 shows the obtained results after LV and MV feeder routing using modified MST algorithm. It depicts the LV feeder path with purple line color and MV conductors by black line color. The LV feeders are connected adequately without passing each other as shown in figure. It demonstrated the modified algorithm has succeeded to solve the feeder routing problem by considering the problem constraints.

\section{Problem Formulation}

In distribution system planning, the geographical distribution of loads density and allocation of feasible candidate substations are the important information in the study year. Based on optimization point of view, 


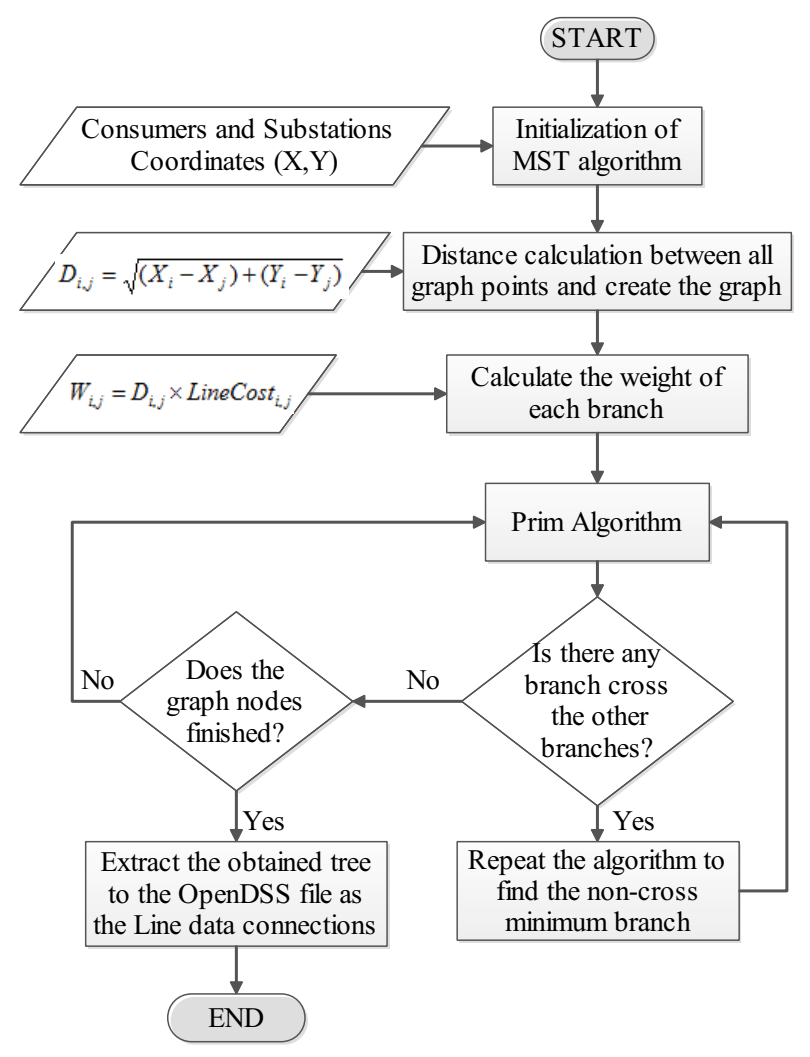

Figure 6. The flowchart of modified MST algorithm in order to solve the optimum feeder routing in distribution network.

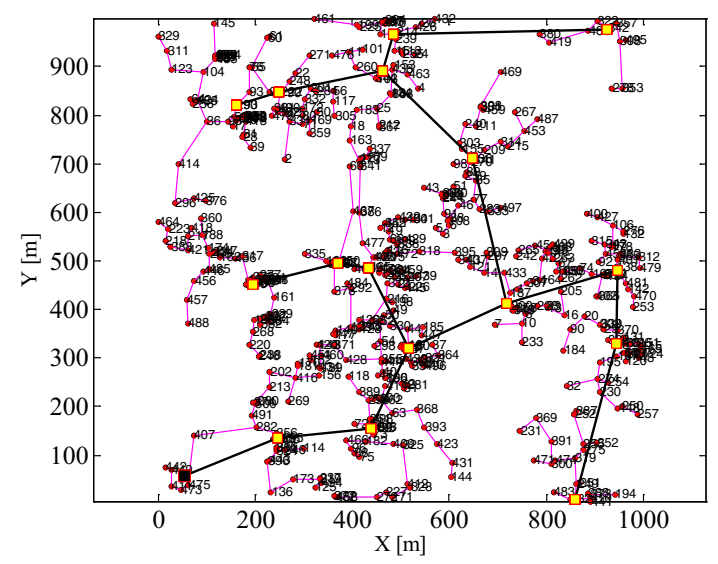

Figure 7. Obtained network after optimum feeder routing for LV and MV in 164 consumers distribution network.

the following constraints must be satisfied in order to optimal distribution substation allocation and feeder routing, which are: a) supplying all the consumers of the networks, b) acceptable voltage drops at the receiving bus, c) Maximum load capacity of all substation, and d) cost minimization of new substation construction. Accordingly, the objective functions of substation placement and sizing can be formulated as follows:

$$
C L=C_{L} \cdot \sum_{i=1}^{n l b} P_{\text {Loss }}^{i} .8760
$$

where, $C L$ is the total losses cost for a study year, $C_{\mathrm{L}}[\$ / \mathrm{kWh}]$ is the cost of real power losses which is provided $\operatorname{in}^{12}\left(C_{\mathrm{L}}=168 \$ / k W /\right.$ year $\left.]\right), P_{\text {Loss }}^{i}[k W]$ is the real power losses at consumer $i$ and $n l b$ is the number of consumers.

The investment cost of substation should be annuitized to able to accumulate with other network costs ${ }^{13}$. Thus, to annuitize the investment cost of distribution network, the following economical consideration should be performed.

$$
\begin{gathered}
V C_{S}=\sum_{j=1}^{n s} C_{\mathrm{var}}(j) \cdot\left(\sum_{i=1}^{n l b} d_{l b}(j, i)\right) \\
F C_{S}=\sum_{j=1}^{n s} C_{f i x}(j) \\
C_{S}=V C_{S}+F C_{S}
\end{gathered}
$$

where $V C_{s}$ is the total substation variable cost, $C_{v a r}(j)$ is the cost of substation $j$ per MVA, $d_{l b}(j, i)$ is the consumer demand $i$ which connected to substation $j . F C_{s}$ represents the total fixed cost of substations and $C_{f i x}(j)$ is the fixed cost of substation $j$. The variable cost of substation included the cost of operation and maintenance, and the fixed cost consists of installation and other related fix cost of substation such as land and equipment prices and etc.

$$
\begin{gathered}
I C=\sum_{j=1}^{n s} C_{S}^{j} C_{l} \\
C C=I C^{\star} \frac{d(1+d)^{T}}{(1+d)^{T}-1}
\end{gathered}
$$

where IC stand for Investment Cost $[\$], C_{S}$ is the total substation installation and operation costs $[\$], C_{l}$ is the total cost of the lines $[\$], C C$ is the annuitized capital cost [\$/year], $d$ is the discount rate and $T$ is the number of operation years. 
Thus, the main objective function that needs to be minimized can be written as follows:

$$
\text { Min } Z=C L+C C+P F
$$

where $Z$ is the total cost function and $P F$ is the penalty factor which is calculated by the optimization constraints. For instance, if the voltage is out of the defined range, therefore the violation amount of voltage will multiply to the constant fine rate (Beta) which can be written as follows:

$$
P F=\sum_{i=1}^{n v}\left(\beta \times \text { Violation }_{i}\right)
$$

where, $n v$ is number of violations and $\beta$ is the fine rate.

The first constraint of distribution network planning is acceptable voltage drop at receiving bus $\left(V_{i}\right)$ which voltage should be within the specified range.

$$
0.95 \leq V_{i} \leq 1.05
$$

The next constraint of distribution network planning is the longest distance of each consumer from the distribution substation which introduced by substation radius based on standard. To consider this constraint the following condition must be considered:

$$
D_{j}^{i} \leq R_{\max }^{j}
$$

where $D_{j}^{i}$ is stand for distance between substation $j$ to consumer $i$ and $R_{\max }^{j}$ is the maximum acceptable radius of substation $j$ that can supply the consumers. Based on the standard, in LV feeder the maximum length of feeder can be up to $0.5-1 \mathrm{~km}$. In urban networks, the length of $11 \mathrm{kV}$ feeders in generally up to $3 \mathrm{~km}$ and for rural networks is up to $20 \mathrm{~km}$.

\section{Result and Discussion}

The fractal based distribution networks generation model tool has been utilized in this paper to generate a distribution network test system. The initial assumptions of the utilized distribution network model are as, $275 \mathrm{MV} /$ LV candidate distribution substations and 500 consumers. Table 1 shows the distribution network consumer demands which generated by the prescribed tool. This case has been used in this paper in order to demonstrate the functionality of proposed algorithms of substation placement and sizing in distribution network and feeder routing in both LV and MV networks.
Table 1. Consumer Demand Data

\begin{tabular}{lccc}
\hline $\begin{array}{l}\text { Type of } \\
\text { consumer }\end{array}$ & Percentage & $\begin{array}{c}\text { No.of } \\
\text { Customers }\end{array}$ & $\begin{array}{c}\text { Maximum } \\
\text { Load }[\mathrm{kW}]\end{array}$ \\
\hline $\begin{array}{l}\text { Residential } \\
\text { (Double Story } \\
\text { house) }\end{array}$ & $90 \%$ & 450 & 5 \\
$\begin{array}{l}\text { Residential } \\
\text { (Bungalow } \\
\text { house) }\end{array}$ & $10 \%$ & 50 & 7 \\
\hline
\end{tabular}

As shown in Figure 5 the number of selected distribution substation is 16 numbers after optimum placement through 275 substation candidates. Table 2 shows the optimization procedure to select the number of required substations with considering the acceptable voltage drop and minimum losses of networks. Table 3 indicates the selected the substation size of transformers after optimization. The voltage drop based on distance for all distribution substations and 500 consumers are shown in Figure 8. It indicates all the buses allocated within the standard range of voltage drop which stated in previously sections. In Figure 8, the dotted line and continuous line indicates $\mathrm{LV}$ and $\mathrm{MV}$ voltage profiles, respectively. An MV/MV substation (secondary substation 33/11 kV) is placed at the fix position which as shown in Figure 7 and the selected substation size is shown in Table 4 .To select the size of substation sizing has been tried to follow the standard of distribution transformer by IEEE/ANSI C57.12.00 ${ }^{14}$.

Table 2. The PSO progress in different number of substations

\begin{tabular}{lccc}
\hline $\begin{array}{l}\text { Number of } \\
\text { transformer }\end{array}$ & $\begin{array}{c}\text { Minimum } \\
\text { Voltage }[p . u .]\end{array}$ & $\begin{array}{c}\text { Total Losses } \\
{[K W]}\end{array}$ & $\begin{array}{c}\text { Best Cost } \\
{[\$ / \text { year }]}\end{array}$ \\
\hline 8 & 0.90492 & 93.11 & 2351657 \\
9 & 0.89132 & 87.59 & 2558751 \\
10 & 0.91855 & 76.68 & 2784625 \\
11 & 0.8682 & 71.64 & 3004456 \\
12 & 0.88147 & 67.23 & 3223352 \\
13 & 0.87815 & 77.24 & 3466781 \\
14 & 0.9315 & 59.01 & 3681601 \\
15 & 0.91676 & 50.74 & 3927347 \\
16 & 0.95365 & 41.33 & 4142015 \\
\hline
\end{tabular}


Table 3. Selected size of MV/LV transformers after optimization

\begin{tabular}{|c|c|c|c|c|c|}
\hline Sub. Name & Xs & Ys & $\begin{array}{c}\text { MV/LV Sub. } \\
\text { capacity [kVA] }\end{array}$ & $\begin{array}{c}\text { Numbers of } \\
\text { consumers }\end{array}$ & $\begin{array}{c}\text { Supplied } \\
\text { consumer }[\mathrm{kVA}]\end{array}$ \\
\hline S1 & 718.77 & 413.42 & 300 & 31 & 159.5 \\
\hline S2 & 463.61 & 890.43 & 225 & 23 & 122.4 \\
\hline S3 & 943.48 & 331.06 & 300 & 32 & 164.7 \\
\hline S4 & 516.17 & 320.09 & 500 & 43 & 227 \\
\hline S5 & 438.00 & 154.33 & 500 & 37 & 201.2 \\
\hline S6 & 947.26 & 480.25 & 500 & 37 & 204.8 \\
\hline S7 & 195.69 & 452.21 & 500 & 44 & 236 \\
\hline S8 & 250.07 & 846.54 & 300 & 28 & 146.6 \\
\hline S9 & 485.23 & 967.16 & 225 & 18 & 95.4 \\
\hline S10 & 859.07 & 8.74 & 225 & 21 & 114.7 \\
\hline S11 & 647.27 & 712.35 & 500 & 39 & 210.7 \\
\hline S12 & 160.42 & 821.21 & 500 & 42 & 220.6 \\
\hline S13 & 434.28 & 486.68 & 500 & 44 & 235.4 \\
\hline S14 & 925.38 & 975.84 & 112.5 & 10 & 55.9 \\
\hline S15 & 246.28 & 136.59 & 300 & 35 & 188.5 \\
\hline S16 & 371.55 & 495.52 & 225 & 16 & 86.4 \\
\hline
\end{tabular}

Table 4. Selected size of secondary transformer (33/11) kV after optimization

\begin{tabular}{lccccc}
\hline $\begin{array}{l}\text { Substation name } \\
{[33 / 11] \mathrm{kV}}\end{array}$ & $\mathrm{X}$ & $\mathrm{Y}$ & $\begin{array}{c}\text { Substation } \\
\text { capacity [kVA] }\end{array}$ & $\begin{array}{c}\text { Numbers of supplied } \\
\text { MV/LV substations [11/0.4]kV }\end{array}$ & $\begin{array}{c}\text { Total apparent power } \\
\text { demand [kVA] }\end{array}$ \\
\hline ES1 & 54 & 58 & 5000 & 16 & 2669.8 \\
\hline
\end{tabular}

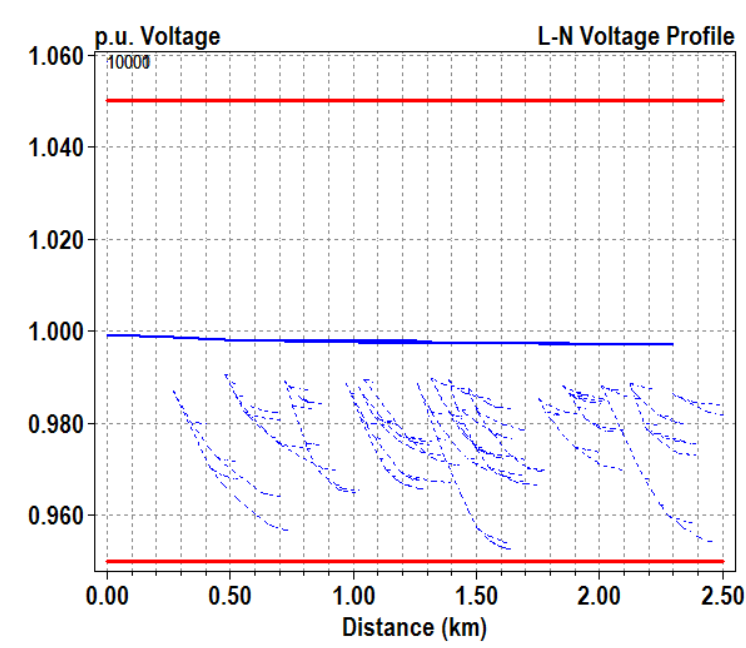

Figure 8. The voltage drop based on consumer and substations distances.

\section{Conclusion}

In conclusion, this paper has proposed the algorithm based on combination of PSO and MST to solve the distribution network planning in terms of substation placement, sizing and feeder routing. The proposed algorithm has performed on the test distribution network model with 500 consumers and 275 candidate distribution substations. The results demonstrate the proposed algorithm has succeeded to find the suitable placement and sizing of distributed generation with adequate feeder path.

\section{Acknowledgement}

The authors would like to gratefully acknowledge the funding support provided by the Ministry of Higher Education Malaysia under the research grant NO. FRGS/2012/FKE/TK02/02/1/F00121. 


\section{References}

1. Boulaxis N, Papadopoulos M. Optimal feeder routing in distribution system planning using dynamic programming technique and GIS facilities. IEEE Transections on Power Delivery. 2002; 17(1):242-7.

2. Najafi S, Hosseinian SH, Abedi M, Vahidnia A, Abachezadeh S. A Framework for Optimal Planning in Large Distribution Networks. IEEE Transections on Power Systems. 2009 May; 24(2):1019-28.

3. Nahman JM, Peric DM. Optimal Planning of Radial Distribution Networks by Simulated Annealing Technique. IEEE Transections on Power Systems. 2008 May; 23(2):790-5.

4. Khator SK, Leung LC. Power distribution planning: a review of models and issues. IEEE Transections on Power Systems. 1997; 12(3):1151-9.

5. Islam S, Ghani M. Economical optimization of conductor selection in planning radial distribution networks. IEEE conference on Transmission and Distribution Conference. 1999; 2:858-63.

6. Kennedy J, Eberhart R. Particle swarm optimization. IEEE International Conference on Neural Network. 1995; 4:1942-8.

7. Taher SA, Karimian A, Hasani M. A new method for optimal location and sizing of capacitors in distorted distribution networks using PSO algorithm. Simulation Modelling Practice and Theory. 2011 Feb; 19(2):662-72.

8. Shamshiri M, Gan CK, Jusoff K, Hasan IJ, Ruddin M, Yusoff M, Engineering E, Utem M, Jaya HT, Tunggal D, Jaya T. Using Particle Swarm Optimization Algorithm in the Distribution System Planning. AJBAS. 2013; 7(3):85-92.

9. Hasan IJ, Gan CK, Shamshiri M, Isamdi BB, Ruddin GAM. Losses Reduction and Voltage Improvement Using Optimum Capacitor Allocation by PSO in Power Distribution Networks. IREMOS. 2013 Aug; 6(4):1219-26.

10. Dugan R. OpenDSS Introductory Training Level I. EPRl. 2009.

11. Gan CK. Strategies for design of future distribution networks [PhD Thesis]. Imperial College; London: 2011.

12. Eajal A, El-Hawary M. Optimal capacitor placement and sizing in distorted radial distribution systems part III: Numerical results. ICHQP, Bergamo, Italy, 2010, pp. 1-8.

13. Gan CK, Mancarella P, Pudjianto D, Strbac G. Statistical appraisal of economic design strategies of LV distribution networks. Electric Power System Research. 2011 Jul; 81(7):1363-72.

14. IEEE Standard for Standard General Requirements for Liquid-Immersed Distribution, Power, and Regulating Transformers. IEEE Std C57.12.00 